María Belén Verón Ponce

Lic. en Trabajo Social (UNC). Becaria de CONICET

E-mail: casadelpan@yahoo.com.ar

\title{
Pobreza y género en los programas sociales «contra la pobreza» en Catamarca
}

\begin{abstract}
Resumen
Se presentan algunos avances de la investigación que responde a la pregunta: ¿Cómo se definen en el discurso de los programas sociales la «pobreza» y las «relaciones de género» en cuanto a: destinatarios de las acciones, estrategias de intervención y contenido de los beneficios? Analizamos los discurso de programas «Emprendedores» de la Dirección de Desarrollo Local y Economía Social y «Pro Familia» de la Dirección de Políticas de Promoción Socio Alimentaria (Secretaria de Desarrollo Social de Catamarca) empleando el método de análisis sociológico del discurso, conforme a la propuesta teóricometodológica de Costa y Mozejko (2001). Considerando el discurso como «práctica y proceso», observamos el proceso de «enunciación» donde el agente que produce el discurso, pone en juego sus recursos diferenciados de relación y competencias,
\end{abstract}

que en un campo de fuerzas busca legitimar su discurso.

Identificamos los destinatarios del «discurso político», luego se explicita las competencias y valores desde los cuales el enunciador buscar legitimarse.

Reconocemos una continuidad entre las conceptualizaciones de pobreza y género (como se construye al enunciatario), las estrategias de intervención que se plantean y el contenido de los beneficios.

Sosteniendo la hipótesis de que si bien en el discurso, los programas sociales se construyen como garantes de derechos, persisten en ellos visiones del sujeto y relaciones de género reproductoras de los roles tradicionales (asignados a varones y mujeres), que impiden el ejercicio pleno de ciudadanía de los mismos.

Palabras Claves

pobreza $\cdot$ género $\cdot$ programas sociales

\section{Introducción}

Cómo se definen en el discurso de los programas sociales la «pobreza» y las «relaciones de género» en cuanto a: destinatarios de las acciones, estrategias de intervención y contenido de los beneficios, es la pregunta que orienta la investigación de la cual se presenta una síntesis. El corpus de análisis está conformado por los programas «Emprendedores» de la Dirección de Desarrollo Local y Economía Social y «Pro Familia» de la Dirección de Políticas de Promoción Socioalimentaria, ambas en la Secretaria de Desarrollo Social de Catamarca ${ }^{1}$.

\footnotetext{
${ }^{1}$ Se seleccionaron programas que si bien en algunos casos o parcialmente son financiados por el gobierno nacional, en el diseño y ejecución intervienen funcionarios y técnicos de la provincia. Ambos fueron diseñados y/o ejecutados entre 2004 y 2006.
} 
Ambos programas fueron presentados como innovaciones de la Secretaría de Desarrollo Social, en la gestión que tiene como titular a la Flga. Marta Torres de Mansilla, quien asume a fines del 2004 y continúa en el cargo hasta la fecha ${ }^{2}$.

Para el análisis discursivo empleamos el método de análisis sociológico del discurso, conforme a la propuesta teórico-metodológica de Costa y Mozejko. Esta perspectiva sostiene que el discurso no es un «producto dado», sino que es «práctica y proceso». El discurso como práctica, reconoce su doble dimensión: «como proceso social y como enunciación» (Costa y Mozejko, 2001: 9). Como proceso, se reconoce al sujeto que produce el discurso y las condiciones con las que cuenta para realizar su trabajo. Estas condiciones sociales de producción limitan o posibilitan la acción o el trabajo de dicho agente, delimitando la competencia que se pone en juego en la construcción de su discurso. La competencia del agente está dada por la «capacidad diferenciada de relación fundada en el control diferenciado de propiedades y/o recursos eficientes, y en las orientaciones de uso y gestión de las mismas, incorporadas» (Costa y Mozejko, 2001: 14). En el campo de fuerzas, cada agente busca construir su legitimidad en el discurso poniendo en juego sus recursos diferenciados de relación ${ }^{3}$.

Respecto al tipo de discurso que analizamos, nos ubicamos en lo que podría definirse como «discurso político» ya que «exhibe un vínculo explícito con las estructuras institucionales de poder y con el campo de relaciones sociales asociado a esas estructuras (partidos políticos y movimientos sociales)» (Verón, 1980: 88).

En este caso, el vínculo con el poder está dado, por un lado, por la pertenencia institucional de los discursos (a un organismo del Estado Provincial) ${ }^{4}$ y, por el otro, por los efectos de los sentidos que produce en sus destinatarios. Esto es explicado por Verón (1980) como una doble distinción del poder entre discursos y sus condiciones de producción (que remite a la problemática de lo ideológico) y las condiciones de reconocimiento (que remite a sus efectos).

Adoptamos esta propuesta teórico-metodológica en la medida que nos permite hacer un análisis del discurso más allá de las operaciones lingüísticas adoptadas para la construcción de un texto. Pretendemos reconocer en los discursos las relaciones que se plantean entre sujetos que conforman un espacio social y disputan recursos materiales y simbólicos. Desde esta perspectiva sociológica, es posible observar las políticas sociales en tanto construcciones discursivas que se proponen la imposición de una determinada visión de la realidad, que devienen en acciones acordes a la misma y que se construyen en un interjuego de poder de diferentes actores en un espacio determinado.

\footnotetext{
${ }^{2}$ Marta Torres de Mansilla comparte con el gobernador Eduardo Brizuela del Moral, la línea interna «Movimiento Renovador» de la UCR, partido que constituye el socio mayoritario de la alianza gobernante en la provincia desde 1991: el Frente Cívico y Social. Cabe aclarar que la asunción de Torres en la cartera social, se sucede al escándalo público que la prensa denominó «El Megafraude de Desarrollo Social», por la que se encuentra actualmente procesado el anterior Secretario (Córdoba Molas), junto a responsables de dos fundaciones locales (IDEAl y Jóvenes en Progreso), bajo la imputación de fraude a la administración pública y falsificación de documentos. En el hecho se investiga el pago a las Fundaciones en concepto de capacitaciones, por la suma de 5 millones de pesos.

${ }^{3}$ En el presente artículo no se presentan mayores detalles del análisis del lugar del agente y sus recursos. ${ }^{4}$ El corpus analizado está compuesto por los Decretos de Creación de Programas, Informes de Gestión, folletería dirigida a los beneficiarios de los programas y el Discurso de Asunción de la Secretaría de Desarrollo Social Marta Torres de Mansilla.
} 


\section{Estrategias del agente para construir su discurso}

El agente que produce el discurso recurre a estrategias que permiten fundar su legitimidad y alcanzar adhesión de sus interlocutores. Los valores que los agentes resaltan en casi todos sus discursos, son:

- la autonomía y libertad, entendida como «libertad» de los padres de familia para responder a las necesidades de sus hijos. Estos dos valores son «otorgados» por la entidad ejecutora, al «devolverles a los padres su capacidad y responsabilidad en la alimentación de sus hijos». Sin embargo, cabe aclarar que la libertad hace referencia a la «libertad de elección de los alimentos», que se pueden comprar con los Vales Pro Familia.

- la responsabilidad, sobre todo la alimentaria, de los padres también se «da», se «permite recuperar», pero también se la «premia», en tanto constituyen acciones exigidas a los destinatarios, como contraparte en los programas alimentarios: «Reunir a cada familia en torno a la mesa del hogar, permiténdoles, además, recuperar su LIBERTAD para elegir, sU AUTONOMÍA para decidir y también su RESPONSABILIDAD respecto, sobre todo, del bienestar de sus hijos $y$, en general, de la calidad de vida de todos sus integrantes» (TNF).

- las grandes ideas del futuro asociado a los niños en la familia. Es llamativa, además, la apelación al «nuestro» dando idea de pertenencia o paternalismo, cuando hace referencia a las familias y sobre todo a los niños, pero también a Ios emprendedores: "CRECER SANO» y asegurar «IGUALDAD DE OPORTUNDIADES» a nuestros hijos, fortaleciendo su capacidad para los aprendizajes y su desarrollo en «FAMILIA» constituyen las bases sólidas de «NUESTRO FUTURO» (TNF).

Los valores sobre los que se construye el discurso de los programas sociales responden a significaciones legitimadas en el contexto social de circulación de esos discursos: «la eficacia en el proceso de imposición de representaciones depende, en buena medida, del recurso a significaciones ya consensuadas en la sociedad donde circulan los discursos» (Costa y Mozejko, 2001: 51).

Asimismo, el agente construye el Yo de la enunciación, es decir el enunciador. En esta construcción estratégica, el agente social cruza oposiciones, resalta recursos, establece alianzas, a los fines de presentarse de manera legítima.

Podemos afirmar que los agentes construyen su lugar «legítimo», en virtud de haber sido «elegidas en confianza» (otorgando respaldo), para desempeñar funciones en el/los cargo/s asignado/s; por la «idoneidad» y el «prestigio del equipo», que se compromete al trabajo y esfuerzo. A su vez, el gobernador de la provincia (quien las designa) encuentra su legitimidad en el hecho de haber sido elegido por el voto del $49.8 \%$ del electorado en un sistema de democracia representativa: «En primer término necesito expresar mi profundo agradecimiento al Señor Gobernador de la Provincia, por la distinción con la que me honra al confiarme en momentos críticos la conducción de un área tan sensible que es también clave para su gestión de gobierno y fundamentalmente para que Catamarca asiente sobre bases firmes su proceso de desarrollo» (DA).

En la disputa por imponer su sentido en la producción y circulación del discurso -en este caso, discurso político-, el agente pone en juego en su enunciado estrategias discursivas que dan cuenta de sus «competencias». Estas 
surgen de la «selección, dentro de alternativas posibles, que resulta comprensible y explicable en cuanto opera desde una posición en un sistema -campode relaciones» (Costa y Mozejko, 2001: 71).

En los discursos que analizamos, identificamos cuatro tipos de competencias sobre las que el enunciador construye su legitimidad:

1. Una primera y evidente estrategia por la cual el enunciador se presenta, tiene que ver con las apelaciones al profesionalismo, al «saber hacer» desde lo técnico- profesional, desde lo eficiente y eficaz. Este es un recurso de autoridad en el que se erige el discurso desde «competencias cognitivas»: «Institucionalizar, profesionalizar y racionalizar el sistema en orden a un mayor rédito social del gasto (...) Implementar un Registro Único de Beneficiarios y un Sistema Permanente de Evaluación y Seguimiento del Estado Nutricional de la Población los que, en concomitancia con mecanismos de control adecuados, permitirán ejecutar eficacia y eficiencia los recursos públicos» (DNF). La idea de control asociado a eficacia y eficiencia en el uso de los recursos se motiva en -y pretende diferenciarse de- las múltiples denuncias a gestiones anteriores sobre malversación de fondos y uso indebido de recursos en la entidad que representa.

2. Asimismo, el agente se construye en su discurso apelando a estrategias que resaltan sus «competencias axiológicas y pasionales» para fundar su legitimidad en tanto diseñador y ejecutor de programas sociales que «pueden cambiar la realidad»: «... proclamar a viva voz que al menos nuestra ideología no ha muerto, que sostenemos los mismos principios, metas y las utopías fundacionales y que como sociedad transitamos un proceso de cambio no acabado. Que los procesos y escollos no deben ni pueden hacernos bajar los brazos y que con esfuerzo renovado vamos a seguir adelante» (DA).

3. El enunciador se construye identificado con las palabras de otro enunciador que lo contiene, (el gobierno provincial) como un «diseñador y ejecutor de políticas integrales» que buscan el «desarrollo sustentable». Esto también funda su legitimidad y competencia para el cargo, respaldada en la elección en la confianza que le/s otorga a las agentes el alto mandatario que, a su vez, se encuentra legitimado para ejercer un cargo de representación democrática electiva. De esta manera, los agentes construyen su discurso y su posicionamiento como enunciadores, legitimados en el marco doctrinario del gobierno provincial: «... generar desde allí políticas de Estado Activas e integrales que permitan promover de manera global las condiciones del desarrollo, dando satisfacción en áreas de infraestructura básica social y productiva, salud, educación, seguridad, trabajo, nutrición, capacitación permanente, fortalecimiento familiar y de la sociedad civil organizada, el recupero de la cultura del trabajo y de apego a la legalidad y la construcción de ciudadanía» (I de G 05/06 y P 07,NF). Los contenidos del discurso centrado en conceptos como «políticas sociales integrales» que «garantizan derechos ciudadanos», forman parte del programa de políticas nacionales que circulan de manera predominante desde la gestión de Néstor Kirchner: «las estrategias discursivas del Gobierno sobre las políticas sociales (...) manifiesta un claro cambio discursivo con respecto a la presentación de los planes sociales de los '90: se recupera el lenguaje de los derechos con lo que ellos implican de universalidad e inclusión. De este modo, incluye a las políticas sociales en un proyecto alternativo de país, al caracterizar a los planes sociales como redistributivos y productivos» (Segura, 2006: 8). 
Sin embargo, a pesar del diagnóstico que relaciona lo económico con lo social, no se encuentran las articulaciones en las estrategias. Respecto a esto, Lo Vuolo et al argumentan la necesidad de atravesar las soluciones al problema de la pobreza, por el plano económico y político-económico: «En una economía capitalista de mercado, el elemento para dilucidar las formas de funcionamiento de las personas son los recursos económicos, no sólo la cantidad que se controla sino también la forma en que se accede a ese control» (Lo Vuolo et al, 1998: 126). En el mismo sentido, Segura (2006: 16) sostiene: «Al no modificar la distribución que realiza el mercado reasignando la riqueza entre los diferentes sectores sociales, la política social del Estado se divorcia de la política económica, se declara incompetente para resolver el problema de la pobreza, y se restringe a los objetivos de paliar/atenuar la situación de la población pobre sin afectar la dinámica del mercado. De este modo, el Estado no asegura derechos económicos y sociales universales, sino que tiende a atender la emergencia social asegurando la supervivencia de una mayor cantidad de personas, y a contener posibles conflictos sociales producto de las condiciones de extrema pobreza».

4. Otra significación respecto al enunciador, lo posiciona como el que ayuda. Este concepto, contradictorio respecto a los anteriores, se articula con una visión de pobreza y con una estrategia para combatirla: «El estado nos ayuda a desarrollar nuestras capacidades» (FE). «Los vales de compra te permiten cubrir lo que necesitás para preparar una comida más variada, nutritiva y saludable para tu familia» (DipVPF). En coherencia con miradas sobre los pobres como «carentes», se entiende la «ayuda» como un acto donativo de quien «tiene» y por eso perpetúa la relación de desigualdad entre los actores (Estado-pobres). Esta visión se corresponde con la que Lo Voulo et alli (1999) denominan «visión caritativa»: se rechaza la pobreza desde fundamentos éticos y se propone la solidaridad hacia los afectados; se desnaturalizan los derechos sociales y ciudadanos, por una «ética personal entre el donante y el receptor», siendo una variante de esta mirada la que convoca a la auto-organización frecuentemente encontrada en los discursos de los programas analizados y en lo que ahondaremos más adelante.

\section{Cómo se construye al destinatario}

Todo discurso construye un enunciador, pero también -y sobre todo- un enunciatario, el Tú de la enunciación. En el caso del discurso político, su característica fundamental es su naturaleza polémica en tanto «explicita el hecho de que existen otros discursos del mismo tipo, que están en relación de oposición o enfrentamiento» (Verón, 1980: 93). Estos discursos, al tiempo que son reconocidos por el enunciador, también son presentados como «falsos». Por ello, se reconoce en el discurso múltiples destinatarios o enunciatarios, de acuerdo al objetivo que el enunciador se propone en su discurso.

Respecto de los destinatarios del discurso político, Verón (1987) distingue al prodestinatario como «destinatario positivo, posición que corresponde a un relector que participa de las mismas ideas, que adhiere a los mismos valores y persigue los mismos objetivos que el enucniador» (Verón, 1987: 16). En el caso de los discursos analizados, los prodestinatarios estarían identificados 
con el discurso de la Secretaría, por pertenecer y/o compartir con el ideario del Frente Cívico y Social, o por recibir los beneficios de los programas que se definen: «...juntos podamos construir un FUTURO MEJOR (...)Para recuperar nuestra LIBERTAD y nuestra INDEPENDENCIA... (DPF).

Aparecen también en el discurso político los contradestinatarios, en tanto actores políticos cuyos discursos y acciones se reconocen pero se presentan como «falsos». En el caso analizado son claramente los «punteros políticos» 0 intermediarios del beneficio que la entidad otorga: «eliminando la figura del puntero (...) Es inadmisible que un centro privado de la Capital pueda estar reclamando bolsones para enfermos celíacos. Repito, estos son Programas para la gente que necesita de políticas activas del Estado y no en beneficio personal o sectorial de nadie» (DA).

Cabe aclarar que la estrategia de «eliminar a los punteros» se anunció e implementó desde el primer momento de la gestión, respondiendo a críticas a gestiones anteriores por corrupción y clientelismo. También aparecen mencionados los «críticos» de la gestión del Gobernador y a quienes pertenecen a su línea interna (Movimiento Renovador) dentro del Frente gobernante: «alguien puede decir que se ve agrandado en estructura, quiero dejar sentado que no significa el aumento de planta de funcionarios respecto de lo que ya venía funcionando...» (DA).

Esta defensa ante posibles críticas se comprende en el contexto de circulación del discurso, marcada por fuertes críticas al gobierno provincial por acciones de corrupción del anterior titular del organismo que se analiza.

Entre los destinatarios del discurso político, también podemos encontrar a los paradestinatarios, en tanto «sectores de la ciudadanía que se mantienen, en cierto modo, 'fuera del juego', y que, en los procesos electorales, son identificado habitualmente como los 'indecisos' (...) Al paradestinatario va dirigido todo lo que en el discurso político es del orden de la persuasión» (Verón, 1987: 17). En el discurso que se analiza, se apela a la ciudadanía catamarqueña como paradestinatario: «...que como sociedad transitamos un proceso de cambio no acabado. Que los procesos y escollos no deben ni pueden hacernos bajar los brazos y que con esfuerzo renovado vamos a seguir adelante» (DA). «... Entonces aquí va un llamado a la sociedad en su conjunto a los fines de que asumamos los valores y la ética en la puesta en marcha de estos Programas...» (DA)

De esta manera, se pretende «mejorar la imagen» de una institución sumida en el descrédito generalizado a raíz de las fuertes críticas y sumar a toda la población a «acompañar el cambio» de gestión.

En adelante, a los fines de responder a la pregunta que nos orienta, analizaremos visiones de los destinatarios (beneficiarios de los programas) en los discursos del enunciador, qué estrategias surgen como consecuencia de esas visiones y qué conceptos de familia y de género prevalecen en los discursos con los que el enunciador construye a sus enunciatarios.

\section{Visiones sobre los destinatarios}

«La gente», como aparece en algunos discursos analizados, es definida de diferentes maneras por su enunciador: 
1. Con capacidades. Discursos que se refieren al/los destinatario/s de los programas como un sujeto con «capacidades» a quien se puede «promover en lo personal y grupal»: "Promover condiciones de real desarrollo humano y social en red, motivando el despliegue de potencialidades personales y de grupo, capaces de generar proyectos de vida independientes y superadores» (DNF).

Capacidades/potencialidades, no sólo de los sujetos sino también de las localidades, que pueden ser tenidas en cuenta en espacios participativos para la generación de políticas públicas: «... contribuir a generar espacios participativos, movilizando los recursos locales y articulando una estrategia local y regional de desarrollo. La elaboración de diagnósticos que reflejen las necesidades, iniciativas y propuestas de implementación de políticas publicas basados en las potencialidades locales y regionales...» (DE).

2. Carente. Esta visión se conecta con las lecturas oficiales sobre la pobreza, que hacen hincapié en la situación de carencia económica de los destinatarios, definidos como «vulnerables», «en riesgo», etc.: «...población en situación de vulnerabilidad socio alimentaria» (DNF). «Familias en situación de carencia alimentaria y vulnerabilidad social...» (I de G 05/06 y P 07, NF).

Esta visión se complementa con la del enunciatario como carente de «saber», de conocimientos, para superar la situación en la que está inmerso, situación que se relaciona con cierta indolencia por parte de los sujetos.

3. Irresponsable e ignorante. Observamos una identificación de los destinatarios como carentes de «saber» que es más claramente evidente cuando se analizan las estrategias de intervención. Encontramos en el discurso referencias, que dan cuenta de esta afirmación: «...Debemos aprender a utilizarlos en las distintas comidas para lograr una alimentación equilibrada, completa, armónica y suficiente» (DPF).

Si bien se trata de una estrategia de intervención, se rescata la síntesis argumental de una obra de teatro -«Los Juicios del Chelco»- que con fines «educativos», ilustra la mirada que el agente tiene sobre los sujetos destinatarios: «Es el último día del juicio. Se lo juzga al vecino. Ya han desfilado los testigos a favor y en contra y tanto el fiscal como la abogada defensora tienen que convencer al juez de la culpabilidad o inocencia del acusado, de no hacerse cargo y de fallarle a su familia y a la sociedad. La abogada decide hacerlo testificar y de esa manera, él se da cuenta de sus posibilidades, de sus capacidades en él ignoradas para generar ingresos, para no depender más de las cajas o vales alimentarios que el Estado le está dando y hacerse cargo de su vida y su familia. El vecino alega en su defensa ignorancia, el fiscal lo ataca por abuso de confianza y por pretender un Estado Paternalista. El juez dicta sentencia: empate. No puede declararlo inocente por su ignorancia sobre el tema, pero tampoco puede declararlo culpable, justamente por lo mismo» (I de G 05/ 06 y $P$ 07, NF).

Este ejemplo que acentúa la «culpa del vecino» por no ser responsable y por pedir al Estado recursos para atender a su familia ${ }^{5}$, nos conecta con la otra

\footnotetext{
${ }^{5}$ Es, además, notable cómo esta estrategia que se propone disparar la reflexión con fines educativos, no toma en cuenta la situación de pobreza que le impide al vecino «cumplir con su responsabilidad» y que por tanto lo habilita a reclamar por un derecho. Por otra parte, en el análisis de situación que propone la obra, no repara en el rol del Estado (ya sea de responsable por la injusticia e inequidad por provoca la pobreza del vecino, o de obligación/ garantía de un derecho). Por el contrariamente, se concluye el relato argumentando la «ignorancia» como limite para juzgar (o no) como culpable al protagonista.
} 
«carencia» marcada en los sujetos destinatarios: la desidia, negligencia, irresponsabilidad, dejadez, en relación a sus obligaciones como padres/madres de familia.

En este sentido, se puede afirmar que existe un mecanismo que responsabiliza a la persona de su situación de pobreza y, por tanto, se plantea estrategias de intervención que «concientizan» o «enseñan» a la persona, para que asuma acciones que la vuelvan responsable de su superación.

Consecuentemente con las visiones de los destinatarios como «carentes, ignorantes e irresponsables», se realizan desde el enunciador diagnósticos de la realidad que ponen la atención estas manifestaciones de la pobreza desde una visión «moral»: «La actual situación de crisis social, moral y ética, en la que operan factores como desempleo, marginación, relativismo ético (todo vale), drogadicción, alcoholismo, violencia, abuso sexual, pérdida de identidad, embarazo adolescente, trabajo infantil, degradación de las instituciones rectoras (familia, iglesia, escuela, justicia)...» (DA).

Paradójicamente se encuentra, como respuesta a este diagnóstico, una crítica a las políticas asistenciales, en relación a sus efectos en los destinatarios (continúa la cita): «... no se soluciona -evidentemente- con la sola política tradicional de la asistencia coyuntural: la entrega de un remedio, una bolsa con comida o de unas cuantas chapas; sólo satisfacen el instante de una necesidad que se repetirá al infinito, sin que el estado de situación mejore; por el contrario, agrava las condiciones de indignidad, dependencia e inmovilismo del que recibe» $(D A)^{6}$. Esta crítica no se revierte en las estrategias de intervención que el agente propone.

Así como se definen visiones de la pobreza y luego estrategias de intervención a raíz de ella, los discursos de los programas sociales configuran ciertas visiones de género que también se legitiman.

1. Visión de la Familia Tradicional

En el discurso de los programas sociales, la familia se identifica desde una concepción tradicional. En cada uno de los folletos analizados, se observan figuras (fotos y dibujos) de familias constituidas como nucleares (padres e hijos) y heterosexuales. Un texto paradigmático versa: «...Nuestra meta es: Reconstituir la FAMILIA, núcleo básico de la sociedad, fortaleciéndola como ámbito de contención afectiva, de sustento, orientación y protección. -Reunir a cada familia en torno a la mesa del hogar...» (TNF).

En principio, identificamos el discurso de programas sociales centrado en la familia como la destinataria «natural» de las acciones de Estado, como un discurso ampliamente legitimado por las políticas sociales nacionales de la gestión actual. Respecto del modelo de familia que prevalece en los discursos de programas sociales que pretenden combatir la pobreza, Arriagada (2007) sostiene que se mira a la familia de la manera más tradicional: «La mayoría de las políticas gubernamentales se han construido a partir de un concepto de familia 'funcional' donde hay presencia de padre y madre vinculados por matrimonio con perspectiva de convivencia de larga duración, hijos e hijas propios y en donde los roles de género están perfectamente definidos: las mujeres

\footnotetext{
${ }^{6} \mathrm{Al}$ igual que en la referencia anterior, llama la atención que lo que se critica de las políticas asistenciales, no está enfocado en los intereses que la motivan (clientelismo), sino en la dependencia e inmovilización que genera en el que recibe. Otra vez la «culpa» o la «responsabilidad» esta en el destinatario.
} 
responsabilizadas de los trabajos domésticos y los hombres de los extradomésticos. Este modelo de familia presupone derechos y obligaciones tácitamente definidos y una interacción constante entre los miembros del grupo familiar, donde subyace un modelo de responsabilidades asimétricas y con relaciones poco democráticas» (Jusidman, 2003 citado por Arraigada, 2007: 54 - 55).

En relación a esta mirada, y analizando específicamente las «desigualdades de género» que desde la visión de familia, desde el Estado, se promueve, Levín et al advierten «la incidencia de algunas políticas públicas en la modelación de las relaciones de género orientándolas hacia formas tradicionales, patriarcales, de organización familiar de base maternal/doméstica. Esta situación interpela a la responsabilidad política del Estado en las acciones gubernamentales dirigidas a la organización de las relaciones sociales en su rol de garante del bienestar general, del acceso igualitario a las oportunidades de ciudadanía y de la participación plena de los sujetos en el sistema democrático» (2007: 2004).

Al observar los roles asignados a la mujer en el marco de los programas sociales, la situación de desigualdades en relación a principios como la igualdad, se agravan.

2. Roles de la Mujer

En principio, el mecanismo de acceso al beneficio del «Pro Familia», recae en la mujer jefa de familia: «La titularidad del beneficio recaerá en el adulto mayor de 18 años que acredite calidad de Jefe de Hogar. En caso de hogares biparentales, será la mujer la titular primera...» (DNF).

De esta manera, queda a cargo de la mujer la responsabilidad «oficial» en relación al programa -se la toma como titular y se le entrega el beneficio- $y$, consecuentemente, en las implicancias de la compra y preparación de alimentos, constituyendo una sobrecarga para la mujer.

Respecto a esta «priorización» de los programas respecto a la mujer, Levín et al afirman: «El centro de atención, protección y regulación pública continúa siendo, prioritariamente, la mujer en el ámbito privado reproductivo -con estructuras familiares, roles y dinámicas tradicionales-, como si los cambios no involucraran responsabilidades políticas y sociales. Por otra parte, las mujeres son constituidas públicamente, y de manera sistemática, como principales destinatarias de la asistencia social -en el marco de la pobreza, desempleo, desigualdad y vulnerabilidad extendida- y se les atribuye a la gran mayoría beneficios y dependencia del Estado y no derechos ni autonomía individual» (2007: 217).

\section{Estrategias de Intervención}

La definición de pobreza (y en este caso la visión sobre los destinatarios) se encuentra relacionada con las estrategias diseñadas para intervenir y modificar dicha situación. Lo Vuolo et al expresan que «los conceptos adoptados para definir los contenidos de un determinado problema social configuran en gran medida los criterios que orientan las acciones emprendidas para modificarlo» (1999: 21). 
En consecuencia, abordaremos a continuación las estrategias de intervención construidas en los discursos analizados, a través de los cuales el enunciador se relaciona con el enunciatario.

1. Garantizar derechos.

Se recurre al concepto de garantía de derechos -aunque no mayoritariamente presente- en los discursos de la Secretaría de Desarrollo Social: «Una política de Desarrollo Humano y Social en serio, sin desatender su obligación de respuesta asistencial ante la emergencia, debe plantearse objetivos de más largo plazo e impacto real sobre las causas del drama social. Particularmente importante, por tratarse del derecho humano más básico y trascendente, desde lo ético y en términos de futuro, la cuestión nutricional ocupa una posición central y relevante. Dijimos y ratificamos: 'con el hambre no se juega ni se trafica'» (DA).

Sobre ello, recordamos la advertencia desarrollada más arriba en torno a los conceptos que circulan («de moda») en torno a las «nuevas políticas sociales» que se imponen desde el gobierno nacional. Observamos que esta mirada, que asienta la estrategia como el «reconocimiento de un derecho», es tomada luego como un apuesta axiologica, ética o moral, movida por valores y no desde el derecho y la justicia. De esta manera, se corre el discurso a las buenas intenciones o la caridad como lo que se erige en nombre de la moral.

2. Brindar ayuda.

Una definición más clara de esta estrategia, debería referirnos a la palabra «ayuda» que con mayor frecuencia encontramos en los discursos del agente enunciador: «El Estado nos ayuda a desarrollar nuestras capacidades» (FE); «Complementar las necesidades alimentarias de familias con alta vulnerabilidad social...» (TPF).

Este sentido otorgado a la estrategia definida por la política social, se relaciona con la visión de pobreza que Lo Vuolo et al (1999) denominan «caritativa». Consiste en rechazar la pobreza desde fundamentos éticos y se propone la solidaridad hacia los afectados. Se desnaturalizan los derechos sociales y ciudadanos, por una «ética personal entre el donante y el receptor», siendo una variante de esta mirada la que convoca a la auto-organización.

3. Asumir la responsabilidad.

Consiste en la generación de acciones por parte de los destinatarios que implican, junto con la responsabilidad por su situación, la búsqueda de soluciones: «-Promover a emprendimientos productivos (...) -Fortalecer espacios asociativos y redes para mejorar (...) Apoyar (...) emprendimientos productivos individuales, familiares y asociativos comunitarios o comerciales...»(DE).

Estas estrategias de intervención requieren del «compromiso» por parte de los destinatarios. Se constituyen como beneficios o «premios» al esfuerzo en la búsqueda de soluciones a su problema. Esta estrategia, que de alguna manera responsabiliza al sujeto de su situación de pobreza, «no le reconoce su «status de ciudadano, en tanto responsable de deberes públicos, pero también 'acreedor' de derechos universales que el Estado debe reconocer y garantizar proveyendo los recursos necesarios para su satisfacción» (Segura, 2006: 4).

4. El control.

Derivada de la mirada que ubica a los sujetos en una postura de irresponsabilidad frente a sus obligaciones, se plantean estrategias que proponen el 
«control» sobre los sujetos: «... se garantiza cuota alimentaria, mientras exista vocación de mandar a los chicos a la escuela» (DA); «...condición de su permanencia en el sistema, el beneficiario deberá acreditar mensualmente, el cumplimiento de las obligaciones a su cargo, a saber: a) Acreditación,... de la permanencia de los menores de 14 años en el sistema educativo. b) libreta sanitaria donde conste el control facultativo de tratamientos médicos...Semestralmente, la autoridad de aplicación evaluará la modificación de variables dentro del grupo familiar, su evolución y eventuales variaciones programáticas que se hubiesen dispuesto, a los fines de la renovación del beneficio y/o la recategorización del mismo» (DNF).

El hincapié en el control sobre las acciones de los destinatarios como parte necesaria de todas las estrategias de intervención de los programas sociales, remite el análisis a la condición de «mérito» para alcanzar los beneficios que determinada política brinda.

Respecto a ello, Lo Vuolo et al advierten: «...se fortalece su componente meritocrático, se observa un debilitamiento de las políticas más universales y un avance de los programas asistenciales, típicos de los modelos residuales. En esto se nota una erosión de las políticas que basan el derecho al acceso en la condición de ciudadano, en beneficio de otras que discriminan en función de las características personales de los que reclaman asistencia» (1999: 188189).

En el mismo sentido, esta estrategia se relaciona con la que sigue, en tanto un sujeto «irresponsable», que no cumple con las condiciones necesarias para acceder a los beneficios, requiere ser educado.

5. La educación

Como la familia «pobre» tiene déficits (no sabe, no puede, no quiere) para cumplir con su objetivo, el Estado se propone como estrategia la «educación». Para ello, capacita: «Difundir mediante acciones de política comunicacional de carácter intensivo... Capacitar y promover la toma de conciencia... Organizar diversos talleres participativos orientados a desarrollar saberes y habilidades en el uso e incorporación de nuevos alimentos...aunque respetando costumbres y pautas culturales, así como en la administración prudente de los recursos, distribución de roles y tareas en el seno familiar, defensa de los derechos del consumidor, formas asociativas de representación y de producción y consumo; concienciar sobre la gestión y ejecución de los Vales Pro Familia... Elaborar material educativo vinculado a la promoción socio alimentaria para apoyatura a las acciones de capacitación...» (I de G 05/06 y P 07, NF).

Si bien se habla de «talleres participativos», se puede inferir en las expresiones un desconocimiento de los intereses y saberes previos de los/as destinatarios/as, porque se afirma que la finalidad de estos es «desarrollar saberes y habilidades en el uso e incorporación de...». También se observa un prejuicio sobre las prácticas de los sujetos en la administración de los recursos, como jefes/as de familia y en lo que concierne a la responsabilidad alimentaria sobre los hijos, ésto relacionado con la visión de los sujetos como ignorantes e irresponsables.

Las expresiones «toma de conciencia», «capacitar», «difundir» tienen su correlato en un determinado modelo de educación, denominado «educación bancaria». Este modelo se caracteriza por ubicar el «saber» en el actor que «educa», mientras que el «educando» carece de saberes, por lo cual requiere 
de la acción educativa unidireccional y vertical para adquirir conocimientos (Kaplun, 1996) ${ }^{7}$.

Respecto de esta mirada de la educación como estrategia necesaria para orientar las acciones de los pobres, Segura identifica una visión de la pobreza como problemática cultural, entendida como «falta de educación que provoca el predominio de deficiencias morales: la falta de capacidad emprendedora o de 'capacidades para el trabajo', y el autoabandono, la vagancia y el facilismo (...) En este caso, la solución es la educación concebida como 'reformatorio social': es necesaria una transmisión de conocimientos y de valores desde los que los poseen hacia quienes no los tienen. La educación les ayuda a 'ordenar y dirigir sus vidas' en todos sus aspectos. Esto, en el plano económico, los hace más eficientes, más proclives al sacrificio y al trabajo, y les 'ayuda a salir adelante por sí mismos'» (Segura, 2006: 6).

6. Educación maternal de las mujeres.

Respecto de la visión de las beneficiarias mujeres, titulares del beneficio del Programa «Pro Familia», podemos inferir que nos encontramos con una doble estigmatización de las mujeres «pobres», ahora también «irresponsables» e «ignorantes» en su función de madres, a quienes se les pide que «tomen conciencia» y asuman su deber en este «nuevo marco de libertad y autonomía en la responsabilidad» como jefas de familia.

En coherencia con esta mirada sobre las destinatarias, el programa incluye en los objetivos específicos, acciones de capacitación que corresponden con prácticas «femeninas» y maternales, por tanto asignadas a la mujer madre: «Capacitar en prácticas de cuidado del embarazo, puericultura, lactancia materna y estimulación temprana, promoviendo conciencia respecto de su importancia para la salud fisica y psico-afectiva del niño» (DNF).

Nari sostiene que la puericultura como disciplina y rama de la medicina, se originó e institucionalizó para el control sobre la vida y los cuerpos de mujeres. Basados en la idea de «debilidad», «fragilidad» o «inferioridad» de la naturaleza de la mujer, se justificaban y legitimaban -a fines del siglo XIX- los discursos médicos y la puericultura que promovía el cuidado del niño a través del cuerpo de la madre (durante la gestación) y luego mediante prácticas de cuidado e higiene que eran «aconsejadas» -cuando no «ordenadas»- de médicos a madres. «La propuesta, científicamente avalada, era contrapuesta al 'caos', la 'ignorancia', la 'negligencia' y la 'desidia' de esos mundo femeninos» (Nari, 2004: 116).

Por lo tanto, podemos identificar en el discurso de los programas sociales

\footnotetext{
${ }^{7}$ Por el contrario, la educación popular propuesta por Paulo Freire (1921-1997) «propone partir del reconocimiento del universo vocabular o del universo temático de los otros. Esto significa una posición política. Las estrategias han sido consideradas como los medios a través de los cuales llevar un poco de orden, racionalidad y claridad (inclusive en términos de 'conciencia crític') a las prácticas socioculturales confusas, desordenadas, irracionales en cuanto más ligadas a la sensibilidad que al entendimiento. (...) Pero en el marco del pensamiento de Freire, las estrategias de comunicación/educación adquieren otro sentido político, ya que Freire propone trabajar con el otro en la búsqueda de sus propias formas de organización, y no ya «para el otro» (lo que significaría trabajar «sobre» o «contra» el otro). De allí que, en esta línea política, desarrollar trabajos o acciones estratégicas de comunicación/educación, significa hacerlo con los otros. $Y$ hacerlo de este modo, significa partir del conocimiento de las prácticas socioculturales de nuestros interlocutores, partir de lo que él llama el conocimiento y reconocimiento del universo vocabular» (Huergo, 2003: 2). En esta perspectiva, la «estrategia» no es unidireccional sino que se retroalimenta, conformando la acción educativa, mutuamente beneficiosa (para el «educador» y para el «educando«).
} 
y en las prácticas que promueve, una doble estigmatización de las mujeres como pobres e ignorantes sobre las que se plantean estrategias de intervención que pueden agravar su situación, en tanto no sólo no resuelven su situación de pobreza, sino que además las sobrecarga de tareas en el ámbito doméstico, quitando posibilidades de autorrealización y autonomía.

Para definir la condición de las mujeres en el marco de estos programas sociales, Levín et al (2007) distinguen el concepto de «status de ciudadanía regulada» que detentan los varones, insertos en la esfera productiva, mientras el resto de la población que queda excluida de este status merece la tutela y protección asistencial por parte del Estado. En este último status se encuentra la «mujer, justificándose su exclusión en el criterio de ausencia de autonomía (...) La ciudadanía de la mujer nace, entonces, bajo condición de tutela del Estado sin posibilidades de autodeterminación. Junto a los sectores pobres, a los niños, discapacitados y ancianos, las mujeres reciben protección, desde entonces, a través de programas sociales o de políticas asistenciales» (Levín et al, 2007: 219).

\section{Contenidos de los beneficios}

El contenido de los beneficios que otorgan los programas sociales (vales de compra, subsidios en dinero y capacitación), las modalidades que adquieren y los mecanismos de asignación, se analizan teniendo en cuenta: los recursos que trasfieren y la estrategia de «focalización»:

1. Transferencia de poder y saber.

Los «beneficios que otorgan» los programas sociales que se analizan se pueden clasificar, siguiendo a Segura, en dos modalidades: «a) la salida comunitarista: en la que la construcción de alternativas es colectiva y participativa («espacios asociativos locales e interinstitucionales»); y b) la salida productivista: que se complementa con la anterior, y que refiere a la unidad de producción en microescala, autogestiva, comunitaria y solidaria («pequeñas unidades económicas productivas individuales y colectivas», «los emprendedores y trabajadores que las integran», «grupos de personas que integren una experiencia productiva», «grupos de pequeños emprendedores»). También se incluye a comedores, huertas y granjas infantiles, familiares, escolares y comunitarios, según corresponda» (Segura, 2006:7).

Respecto a esta clasificación, podemos afirmar que uno de los programas analizados convoca a esta estrategia de manera formal: "Se financiaran proyectos productivos en las siguientes líneas: Emprendimientos Productivos Asociativos de Autoconsumo (...) Emprendimientos Productivos Asociativos comerciales (...) En todos los casos el Fondo no reintegrable será otorgado a la asociación emprendedora o Emprendedor Ejecutor que lo destinará a la compra de insumos y bienes necesarios...» (DE).

El programa «Pro Familia» que se propone una asistencia más directa a través de la transferencia recursos (alimentos o vales de canje) como estrategia central, también convoca a la autogestión: «Además podés asociarte con amigos, vecinos o parientes para obtener una mayor cantidad de productos comprando a mejor precio. Cultivando verduras en una Huerta Familiar o Co- 
munitaria, Plantando árboles frutales, Criando animales de granja para aprovechar sus carnes, leche, huevo, etc.» (DNF).

Este tipo de beneficio se encuentra relacionado con la visión de los sujetos y la estrategia de intervención del que forman parte: transferencia de recursos económicos para los sujetos «carenciados» y transferencia de «saberes» (capacitación), para los carentes de «saber».

2. Focalización «equitativa».

En el programa alimentario, se fundamentan una serie de operaciones técnicas para reasignar una segunda focalización (la primera estaría dada por los criterios de ingreso al programa), a fin de otorgar mas recursos a quienes tengan más «miembros focalizados» en su grupo familiar. Se argumenta la superación de la inequidad en la que el programa cae al «darle más a algunos pobres».

Suponemos que en la racionalidad de la lógica de focalización, esta argumentación es válida. Respecto a ello, recordamos junto a Grassi et al cómo entre las medidas de ajuste recomendadas en el Estado neoliberal, «los pobres devienen en una nueva categoría identificatoria, en sujetos legítimos de las políticas focalizadas de asistencia» (1999: 16). Estas medidas encuentran su correlato ideológico con «el modelo de acumulación, en el dominio del mercado hay, naturalmente, ganadores y perdedores, fuertes y débiles, los que pertenecen y los que quedan afuera» (1999: 16). Más aún, las autoras continúan argumentando acerca de los dispositivos ideológicos que sustentan este estado de cosas: «El modelo neoliberal construye su legitimidad sobre el develamiento y, a nivel de las políticas sociales, la estrategia de la focalización es la expresión genuina del reconocimiento de la potencial existencia de grupos excluidos (...) La pobreza es entonces un estado potencial en un orden que se naturaliza» (1999: 20).

\section{Conclusiones}

La propuesta del análisis discursivo desde una perspectiva sociológica, nos permite identificar el agente que produce el discurso (en este caso la Secretaría de Desarrollo Social) individualizado en dos personas que cuentan con determinados recursos de poder.

Estos recursos: capital social (relaciones, confianza de sectores gobernantes, etc.), saberes (conocimientos o desconocimiento de temas sobre los que se ejecutan políticas) y legitimidad (otorgada por voto mayoritario), son puestos en juego por el enunciador en la construcción de un discurso político.

El discurso pretende fundar su legitimidad en diferentes competencias, a fin de conseguir la adhesión de sus interlocutores: la estrategia de «saber hacer» (desde lo técnico- profesional y de manera «eficaz»), el «valor para cambiar la realidad», mediante el «diseño y la ejecución de políticas integrales» y «garantizando derechos» en contraposición a la estrategia de «brindar ayuda». En todos los casos, el enunciador se presenta como un «héroe» que puede cambiar las viejas políticas sociales (asistenciales y clientelares) que sostenían los «punteros políticos» en (o con el apoyo de) la misma entidad que se estudia.

Basados en los valores de la «autonomía», la «libertad» y la «responsabili- 
dad» (sobre todo asignados a los padres/madres de familia), el discurso de las políticas sociales asistenciales, pretende «incluir» al destinatario en las acciones destinadas a superar la pobreza.

En este contexto, identificamos que el enunciador construye al enunciatario (destinatario de las acciones de los programas) como «carente», «irresponsables» o «ignorante» sumido en una situación de desidia que lo llevó a caer en la pobreza. Ante esto, el Estado se propone como estrategia de intervención, acciones que redundan en transferencia de recursos monetarios (préstamos, subsidios) y saberes otorgados como «capacitaciones» que le permitirían al pobre, derrotar sus deficiencias morales (vagancia, irresponsabilidad) y tener los conocimientos necesarios para superar su situación de pobreza. En este sentido, se arbitran estrategias de «control» sobre la vida y las prácticas de los padres y madres de familia, a fin de dar cuenta de que efectivamente cumplen con las responsabilidades familiares y por tanto se hacen acreedores de los beneficios de los programas.

Paradójicamente también, encontramos en las definiciones de los destinatarios, a un «sujeto con potencialidades» que en consonancia con las políticas nacionales utiliza como estrategia discursiva el «convertir 'activos' (recursos escasos de los pobres) en satisfactores de sus necesidades. Esto requiere de una revalorización y economización de las relaciones de reciprocidad no mercantiles, menos institucionalizadas a nivel local, como la autoayuda, por medio de un proceso de asignación de valor económico a estos vínculos, denominados en el sistema discursivo del desarrollo Humano, como capital social» (Alvarez, 2005: 83).

Respecto de las visiones de género y de familia, encontramos una identificación con el modelo tradicional que diferencia mediante la separación de ámbitos público/privado, una división de roles en la organización familiar, asignando a la mujer/madre de familia, el deber exclusivo sobre los hijos y las tareas domésticas.

El Estado refuerza la heteronomía de las mujeres, al asignarles la titularidad de los beneficios que otorga, duplicando la «estigmatización vergonzante». Entre las estrategias de intervención, que se propone al respecto, se cuenta una determinada «educación para mujeres» (puericultura, nutrición, etc.) cuyo objetivo se orienta a la reafirmación del «rol maternal». De esta manera, las políticas sociales asistenciales, refuerzan el modelo tradicional familiar, las relaciones de género asimétricas y patriarcales, sobre una base «maternal/ doméstica».

No obstante, se expresa en el discurso, una estrategia de reconocimiento de derechos, que guarda relación con la estrategia discursiva del gobierno nacional, pero que a nuestro entender, no puede encontrar su correlato con mecanismos focalizados de otorgamiento de beneficios, en tanto promueven una configuración identitaria «vergonzante» de los sujetos destinatarios (Grassi, et. all. 1994).

La estrategia de «brindar ayuda» también se encuentra reflejada en los discursos y en este caso, se relaciona con la mirada sobre los sujetos pobres con «carencias morales» y que por tanto, requieren de «acciones solidarias» para modificar una situación que se encuentra naturalizada y por la que -por lo tanto- no se indaga sobre sus causas. 
En este sentido, se identifica una estrategia recurrente por parte del Estado de promover al destinatario en «asumir la responsabilidad» que le compete como padre de familia y para ello, instrumenta mecanismo de control que permite reconocer a quienes se «merecen» (y quienes no) ser beneficiarios de un programa. En la misma tensión, se propone educar para la responsabilidad.

Esta primera aproximación al discurso de los programas sociales en torno a la pobreza y el género, y a sus estrategias de intervención, nos permite la identificación de categorías que ayudan a comprender la contribución de los mismos, a la construcción de las identidades de género (objetivo siguiente en la investigación).

El enfoque metodológico, permite por su parte, comprender las relaciones de poder en la disputa por la construcción de las políticas sociales, donde el Estado se constituye como agente poseedor monopólico del capital simbólico, en un campo burocrático de fuerza, en tanto puede «nombrar» y «certificar»con total legitimidad, a través de sus actos oficiales (Bourdieu, 1997: 113-115).

El efecto instituyente y monopólico del Estado en las estructuras subjetivas y objetivas que conforman la realidad social, es observado y analizado a través de sus múltiples mecanismos de constitución y/o institución, de la que los programas sociales, no se encuentran ajenos.

Por ello, el propósito de indagar sobre las visiones de pobreza y género en los programas sociales, se funda en la intención de reconocer las pretensiones «no naturales», sino «políticas» de configurar un orden social determinado.

\section{Bibliografía}

ALVAREZ LEGUIZAMÓN, S. «La invención del desarrollo social en la Argentina» en: ANDRENACCI, L. (Comp.) Problemas de política social en la Argentina Contemporánea. Prometeo Libros, UNGS, 2006.

ARRIAGADA, I. «Transformaciones de las familias y políticas públicas en América Latina» en: LEVIN, S. y CARBONERO, M. (Comp.) Entre Familia y Trabajo. Relaciones, conflictos y políticas de género en Europa y América Latina. Rosario, Homo Sapiens Ediciones, 2007.

BOURDIEU, P. «Espíritus de Estado. Génesis y estructura del campo burocrático» en: BOURDIEU, P. Razones Prácticas. Barcelona, Anagrama, 1997.

COSTA, R Y MOZEJKO, D. El discurso como práctica. Lugares desde donde se escribe la historia. Rosario, Editorial Homo Sapiens, 2001.

GRASSI, E. HINTZE, S., NEUfELD, M. R. Políticas Sociales, Crisis y Ajuste Estructural. Buenos Aires, Editorial Espacio, 1999.

HUERGO, J. El reconocimiento del 'universo vocabular' y la prealimentación de acciones estratégicas. Centro de Comunicación/ Educación. Facultad de Periodismo y Comunicación Social, UNLP, 2003.

KAPLÚN, M. El comunicador popular. Buenos Aires, Lumen-Hvmanitas, 1996. 
LEVIN, S.; CAMPOSTRINI, A; SOSA, R y VORAS, C. «La política de género en las políticas públicas en Argentina» en: LEVIN, S. y CARBONERO, M. (Comp.) Entre Familia y Trabajo. Relaciones, conflictos y políticas de género en Europa y América Latina. Rosario, Homo Sapiens Ediciones, 2007.

LO VUOLO, BARBEITO, PAUTASSI Y RODRÍGUEZ. La pobreza...de la política contra la pobreza. Buenos Aires, Miño y Dávila Editores, CIEPP, 1999.

NARI, M. Las Políticas de la maternidad y maternalismo político. Buenos Aires (18901940). Buenos Aires, Biblos, 2004.

SEGURA, S. La reproducción de la exclusión en el discurso oficial. Las nuevas políticas sociales en la Argentina (2003- 2005) Avances de investigación. Proyecto «Prácticas discursivas: competencia y espacio de posibles». Centro de Investigaciones de la Facultad de Filosofía y Humanidades de la Universidad Nacional de Córdoba (UNC), 2006 (mimeo).

VERÓN, E. «Discurso, poder, poder del discurso», en: Anais do primeiro colóquio de Semiótica. PUC- Edições Loyola, Rio de Janeiro, 1980.

VERÓN, E. «La palabra adversativa. Observaciones sobre la enunciación política», en: VERÓN, E. et. all. (Comp.), El discurso político. Lenguajes y acontecimientos. Buenos Aires, Hachette, 1987.

\section{Corpus}

Decreto Acuerdo N. 715 de aprobación del Programa Integral de Promoción Socio Alimentaria para el Desarrollo Sustentable «Nuestro Futuro» (DNF).

Discurso de asunción de la Secretaria de Estado de Desarrollo Social, Marta Torres de Mansilla, pronunciado el 29 de Octubre de 20004 en el Salón de Acuerdos «Fray Mamerto Esquiú» de Casa De Gobierno (DA).

«Informe de gestión. Programa Integral de Promoción Socio Alimentaria para el Desarrollo Sustentable Nuestro Futuro. 2004 - 2006 y Proyección 2007» (I deG 04/06 y P 07 NF).

Decreto Acuerdo de aprobación del Programa «Emprendedores». En cuyo anexo se encuentra el «Encuadre conceptual, objetivos generales y modalidades del Programa» (DE).

«Informe de gestión. Programa Emprendedores 2005 - 2006 y Proyección 2007» (I de G 05/ 06 y $P 07 \mathrm{E})$.

Tríptico «Programa Integral de Promoción Socio Alimentaria para el Desarrollo Sustentable Nuestro Futuro» (TNF); díptico «Programa Integral de Promoción Socio Alimentaria para el Desarrollo Sustentable Nuestro Futuro» (Dip. NF) y Un folleto doble faz denominado «Vales de compra Pro- Familia» (Dip VPF).

Folleto doble faz «Programa Provincial Emprendedores» (Dip. E). 